\title{
An Experimental Investigation of Magnetically Impelled Arc Butt Welding of Pipes: A Review
}

\author{
Abdul Khadeer Sk ${ }^{\dagger}$ and Naseeb Khan ${ }^{\ddagger}$ \\ †Department of Mechanical Engineering, Vidya Jyothi Institute of Technology, Hyderabad, T.S., India \\ ‡Department of Mechanical Engineering, Shadan College of Engineering and Technology, Hyderabad, T.S., India
}

Received 05 March 2018, Accepted 08 May 2018, Available online 12 May 2018, Vol.8, No.3 (May/June 2018)

\section{Abstract}

This paper describes a new development of circumferential welding of pipes. Circumferential butt welds are commonly used to join pipes in various industries, including power plants and automobile industries. Magnetically impelled arc butt welding process is a hybrid welding technique. It uses a rotating electric arc as its heat source and is known as efficient method for pipe welding. In this process heat is evolved prior to forging by an arc generated between two coaxially aligned pipes, this arc rapidly rotates along the circumferential edges of the pipes to be welded due to the electromagnetic force exerted by the interaction of arc current and magnetic field generated by the external magnetic system. The entire weld over the full joint thickness is made in one single operation, instead of using several passes as in conventional welding. The main emphasis of this review is to describe the different works carried out in the past which help full for providing the information for the future development of research work Present study exposes the different works that has been done in the past for improving the weld quality.

Keywords: MIAB welding, Rotating Electric Arc, Upsetting and Magnetic flux.

\section{Introduction}

Magnetically impelled arc butt (MIAB) welding is a special electric arc welding process falls under the category of pressure welding method, which is used for welding of hollow circular sections.

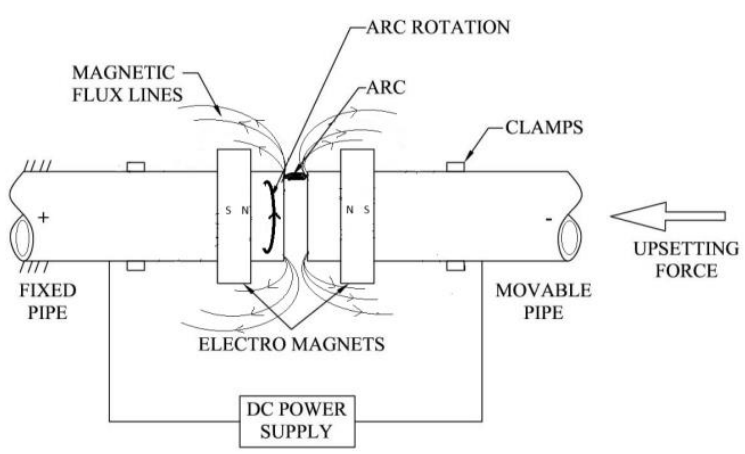

Fig.1 Schematic Diagram of MIAB Process

This process utilizes the rotating electric arc as a source of heat. In this process two tubes or pipe edges are well secured and clamped coaxially, one pipe is fixed and another pipe is movable. A magnetic field is generated either with permanent magnet or

*Corresponding author's ORCID ID: 0000-0003-4442-9354 DOI: https://doi.org/10.14741/ijcet/v.8.3.8 electromagnet is wound near butted edges of the pipe and DC arc is struck between the end of the pipes separated by a fixed small gap. The initiated arc on circumferential point will start rotating around the peripheral edges with a very high speed due to the interaction with radial magnetic field generated by magnets according to the Fleming's left hand rule. After the arc rotted for some time, both pipe ends will be heated up sufficiently, at the end heavy upset pressure is applied to get the welding.

The radial component of the magnetic flux density $\mathrm{Br}$ and the axial component of the welding arc current Ia interact with each other exerting a force on the arc. The mathematical expression of this electromagnetic force is given in equation (1). This force impels the arc along the peripheral edges of the tubes.

$F_{B r}=K \cdot I a \times B r$

Coefficient $\mathrm{K}$ depends on the value of the arc gap between the two tubes to be welded. The force exerted on the arc current influences the speed of the rotating arc. Therefore, it is clear that adjusting the strength of the magnetic field, the magnitude of the arc current, or the width of the arc by changing arc current plays an important role on the speed of arc. In particular, by sharply increasing the welding current for a short time just prior to upset, a rapid expulsion of molten metal occur which enables cleaning action. 


\section{Literature}

In this study (Akira Taneko et al 1987) the arc rotation velocity during MIAB welding of steel pipes was analyzed. An experiment was conducted to investigate the relationship between the arc rotation velocity at various points along the pipe circumference in the early stages of MIAB welding of steel pipes and the method of Supplying the welding current to the pipes and used a voltage detector at various locations inside an alloy steel pipe, an oscilloscope and a high speed video camera to measure arc velocities and arc angles. In particular, they studied the relationship between arc velocity, arc, angle and the position at which power is supplied to the tubes.

(Kuchuk-Yatsenko et al. 1988) focused on arc behavior during MIAB welding of a tube to a plate. In this type of joint, the displacement of the arc from the ID to the OD was reportedly more pronounced due to the magnetic blow resulting from the interaction of the arc and the induced magnetic field. This creates a greater concentration of magnetic lines of force on the ID of the tube, which pushes the arc outward. They concluded that high quality welded joints can be produced only by controlling the radial displacement of the arc.

This paper presents (S. Mori et al,1989) a study of welding conditions and procedures for achieving the butt welding of aluminium or aluminium and copper small bore pipes In the welding of non-magnetic materials, sufficient magnetic flux density to enable welding to take place can be achieved by inserting an iron core into the pipes. In the welding of aluminiumcopper joints, taking into account factors such as the number of rotations of the arc, melting state of the aluminium pipe end face, etc, it is effective to set the aluminium on the negative side and the copper on the positive side obtaining good properties of joint.

This study (Sato et al. 1990) provides an explanation of why, when pipe wall is thick, The arc first rotates at a low speed at inner edge of the pipe and then, as the heating time is increases moves to the outer edge where it rotates at a high speed. And experimental trails are conducted on various thickness of pipes, they concluded in the initial period the arc rotates slowly at inner surface due to low magnetic flux density at inside due to the fact that the lines of magnetic flux absorbed by the pipe material and the cause of this is magnetic blow of arc produced by the difference between the inner and outer magnetic fluxes and also the magnetic variation is caused by temperature rise in the region. The reason of arc revolves at high speed is due to more magnetic flux density at outer edge. Phototransistors were used to assess the movement of the arc. Two voltage detection probes are kept at inside and outside of the tube at interface to know the arc location position and thermocouples are used to measure temperature. Measurement of flux density is carried out by positioning a Gauss meter.
(Kachinskiy et al. 2002) attempted to investigate the arc behavior during the welding of hollow parts with wall thickness, greater than $6 \mathrm{~mm}$. In general, it is a challenge to weld thick walled components due to the tendency of the arc to concentrate on the ID of the component in the MIAB welding process thus resulting in uneven heating. In this work, the importance of controlling the axial component of the magnetic field was emphasized. The ability to alter the axial component of the magnetic field allowed for precise control of the radial position of the arc in the joint. This produces a uniform heating and, thus better quality welds. Such fine maneuvering of the arc can be made by regulating the magnetic field strength on one side of the joint relative to that on the other side. Photoelectric cells and galvanometers were utilized to study the arc movement. This work also postulated that the anode and cathode spot sizes of an arc should be relatively larger than the wall thickness to achieve even heating. During this research work arc rotation pattern and arc movement control have been established.

(J-W Kim et al, 2006) developed a two-dimensional finite element model for the analysis of magnetic flux density distributions produced by electromagnets at the MIAB weld joint. The primary objective was to establish a relationship between the strength of the radial magnetic field at the joint and the quality of the weld joint between two steel pipes. This concept was based on the knowledge that a stronger magnetic field produces a higher force on the arc, resulting in faster arc speeds and more uniform heating. The authors concluded that it is important to maintain maximum flux density at the joint for best weld quality. Therefore, the design of the electromagnet system is very important, as is the exciting current applied to the electromagnets. And it has been stated that the magnetic flux density is dependent mainly on the gap size between the two pipes, the position of the exciting coil that generates the magnetic field, the exciting current in the coil, and the relative permeability of the pipes. The magnetic flux density between the pipes increases with the increase in exciting current and the decrease in gap size of the pipes

(Leigh Fletcher et al, 2006) presented a new perspective from a development project to implement the technology in the field construction of new pipelines in Australia. In this study, a prototype MIABwelding machine was designed and built, one that was capable of welding natural gas pipelines and to make welds in DN 150 pipe complying with the performance requirements of the Australian petroleum pipeline standard AS2885.2. An extensive review and an experimental assessment of the MIAB-welding process were made in the study. The article emphasized that MIAB is a suitable process for the welding of oil and gas pipelines in diameters up to DN450 and thicknesses up to $10 \mathrm{~mm}$.

This paper (S.Arungalai Vendan et al,2008) presents modeling of magnetic flux distribution for magnetically impelled arc butt welding of steel tubes using finite element analysis. The relation between 
magnetic flux density and the interdependence of MIAB welding parameters such as gap size, exciting current in the coil, and coil position from the weld center, which influence the electromagnetic force generated in the welding process were illustrated with a three dimensional finite element model, this facilitates effective design of magnetic set up in MIAB welding process.

(S.Arungalai Vendan et al,2009) has discussed the attempts made to develop a MAIB welding laboratory equipment for understanding the significance of various process parameters and presented the details of the results and the conclusions of the experimental trials conducted on the MIAB developed module. Further, nonlinear electromagnetic analyses have been performed to determine the magnetic field and electromagnetic force distribution in MIAB process using finite element package ANSYS. The results of the analysis are compared with the experimental data for steel tubes. The results of finite element analysis establish that the magnetic flux density in the tube gap region is directly proportional to the exciting current and inversely proportional to the gap and the distance of the electromagnetic coil from the weld line. The finite element models are further used to find the magnetic flux density and electromagnetic force distribution in the MIAB welding process for different tube diameters and thicknesses

This paper (S.I. Kuchuk-Yatsenko et al 2010) gives the results of the investigation of the weldability of pipes of low-carbon steels for application in the pipelines for various purposes, as well as the results of metallographic and mechanical property investigations of welded joints. Results of mechanical tests showed that strength and ductile properties of welded joint are at the level of the characteristics of the parent metal. The Structure of HAZ metal in MIAB welding is mainly similar to the structure of similar joints of pipes made by the flash-butt welding (FBW), but there are differences in the formation of a central part of the joint. , in MIAB welding the HAZ is much narrower than in FBW that provides the formation of a finer-grain structure. They carried out investigations showed that the structure and mechanical properties of joints of pipe steels $\mathrm{X} 70$, made by MIAB welding, are very similar to those of FB-welded joints. Therefore, the systems and methods of non-destructive testing and inprocess control, accepted in FBW, can be similar. The machines have been developed for MIAB welding of pipes and pipelines, providing welding in the field and stationary conditions

This paper (D. Lordachescu et al, 2010) presents the performances of a new developed longitudinal magnetization system, which consists of several small peripheral solenoids disposed around each tube, designed to assure the magnetic flux concentration on the tube wall and was used to investigate the interaction between the arc and the magnetic field in case of MIAB (Magnetically Impelled Arc Butt) welding of low carbon steel thin-walled tubes. The paper also discusses the process main stages based on corresponding images resulting from process monitoring, from arc initiation to the emergence of molten metal when upsetting starts and the weld is formed. Although the welds can be made without any shielding, nitrogen or other reducing or inert gases may be used to improve the joint quality. The authors identified, defined and characterized six different process phases: arc initiation, beginning of arc rotation, arc transitory stage, arc stable rotation, arc instable rotation ("breaking"), and tubes upsetting. In MIAB welding the gap between pipes, has a major influence on process stability, Moreover, in MIAB case the magnetic field value in the tubes gap influences the arc rotation, but its magnitude depends also on the distance between the magnetization shells. The microstructure of the welds revealed a coarse grained structure in the centre line with acicular ferrite, bainite and pearlite formed upon rapid cooling. An increase in hardness was observed in St37 up to 240 HV0.5, which is well below the martensitic level, but within the range of bainite.

This paper (S.I. Kuchuk-Yatsenko et al 2010) reveals magnetically-impelled arc butt welding of automobile parts including compact hollow parts of steering rod, shock-absorber and torque rod, are described. Results of metallographic examinations as well as evaluation of mechanical tests, proving the high quality of welded joints, are presented. Mechanical tests of welded joints were performed in accordance with accepted procedures at the automobile plants They include full-scale rupture tests and also local bending of segments of circumferential welds. Metallographic examinations of welded joints of parts of steering rod and shock-absorber was carried out in the LECO device M 400 at $1 \mathrm{~N}$ load and $100 \mu \mathrm{m}$ pitch, to reveal the microstructure of welded joint. It was found as a result of investigations that the welded joint parts of steering rod and shock-absorber has no structures, changing significantly the properties of metal as regards to the parent metal. The bainite-ferrite structure is dominated in the structure of welded joints.

In this paper (S.Arungalai Vendan et al,2011) several experimental trials are conducted by varying different current, voltages and gap between two tubes on T11 low alloy steel tubes of $48 \mathrm{~mm}$ diameter and $6 \mathrm{~mm}$ thickness on specially made MIAB welding equipment. Initial experiments are conducted with magnetic coil set up and later it was modified with a solid core design to knowing the effect of magnetic materials. Several trails are conducted on ferrite magnets and alnico magnet materials by maintaining same process parameters used in previous trials. There is no noticeable change in the arc behavior are observed. This implies that only the magnetic field set up by the magnet governs the arc rotation and the material of the magnet does not play any significant role in the MIAB welding process and concluded that a minimum of $200 \mathrm{~A}$ current and $2 \mathrm{~mm}$ gap is required to get a good quality of weld. 
This paper (D. Lordachescu et al, 2011) presents the MIAB welding of thin walled tubes achieved with an original longitudinal magnetization system, designed to assure the magnetic flux concentration on the tube wall and for improving the arc rotation stability. The magnetic system for each tube is made of 8 solenoids [4 coils on each half-shell], which are connected in series, and are working positioned in parallel with the tube longitudinal axis on the periphery of both the tubes. In MIAB welding the gap between pipe edges, has a major influence on process stability, the magnetic field value in the tubes gap also Influences the arc rotation, but its magnitude depends on the distance between the magnetization shells. The magnetic field increases with the magnetization current and the surface temperature of the starting and ending phases of MIAB welding was achieved by using the infrared camera. The paper also discusses the process main stages based on the corresponding images resulting from process monitoring, from arc initiation to the emergence of molten metal when upsetting starts and the weld is formed. Different welding experiments were made using low carbon steel tubes of $25.4 \mathrm{~mm}$ outer diameter (OD), $3 \mathrm{~mm}$ thickness.

This paper (S.Arungalai Vendan et al, 2011) presents a brief description of various non destructive tests carried out on the MIAB welded joints. Radiography test is performed on the welded specimen under the non destructive tests. Further, metallographic X-ray diffraction examinations [micrograph, macrograph and SEM] were carried out on the welded specimens. Finally, examination is performed on the MIAB welded specimens to observe the strain developed at the welded joint and the chemical composition of the weld and the base metal. Macro and micro structural analysis shows a good bonding and micro structural integrity in the weld region and X-ray diffraction analysis emphasizes the expulsion of impurity phases in MIAB welded joints making the weldment free from inclusions.

This study (S.Arungalai Vendan et al, 2012) emphasizes the feasibility of Magnetically Impelled Arc Butt(MIAB) welding process for joining alloy steel tubes for pressure parts. The welding current and the welding time are divided into three and four stages respectively. For each trial, either the current in stage II is varied or the time for stage III is varied while maintaining the other input parameters constant. Further, the strength of MIAB welded specimens are examined by subjecting the welded specimens to various destructive tests. It is observed that the weld region is stronger than the base metal in most of the cases. In the next part of the study, the characteristics of MIAB welded joints for T11 steel tubes are compared with those using flash butt welding and induction pressure welding that is presently employed for alloy steel tube joining in pressure parts. It is found that the manufacturing time and incurred cost per weld drastically reduces while simultaneously increasing the productivity.
This paper (Berna Balta, et al, 2014) presents how to design and test vibration induced truck chassis brackets via magnetic impelled arc butt welding. Design of MIAB welded parts using Finite element (FE) techniques and testing the parts with Road Load Data (RLD) tests is explained. Natural frequencies of the parts are calculated, and then, frequency response FE analysis has been performed for worst case conditions Correlation of the design has been performed via reallife tests with RLD data. It has been shown that MIAB welding can be applied to the parts working under vibration load. Quality of MIAB welds are tested with two destructive tests i.e bending and petal test. It has been proven that, qualitative magnetic arc welding processes result in slightly increased ultimate tensile strength values around the weld line. In this paper, fender bracket will be modeled and tested as a case study tested parts and FE analysis results are compared. It has been revealed that, magnetic arc welded fender bracket shows no failure and MIAB welded parts are suitable for vibration induced parts.

This paper (R.Siva Sankari, et al,2014) presents the investigations carried out on MIAB welding trials of carbon steel tubes with varying upset current. Upset current is the short pulse of high current applied prior to upset. It plays a significant role in expulsion of molten metal and impurity from weld interface. This study aims at studying the effect of upset current on weld properties. Carbon steel tubes of SA-210 Grade A have been chosen with outside diameter of $44 \mathrm{~mm}$ and thickness of $4.5 \mathrm{~mm}$. Mechanical and micro structural characterization of MIAB weldments was carried out Upset current has a significant effect on weld microstructure. Lower upset current has detrimental effect on weld tensile strength due to incomplete expulsion of decarburized zone. In tension test fracture take place in weaker region, as Samples welded with lower upset current have a distinct decarburized zone hence fracture take place at weld due to weaker microstructure. In samples welded with higher upset current strengthening takes place in the weld interface due to formation of acicular ferrite. Acicular ferrite is the preferred microstructure in weld interface as it has higher strength and toughness .Upset current of minimum $800 \mathrm{~A}$ is required to remove decarburized zone.

(R.Siva Sankari, et al,2015) have studied MIAB welding of low alloy steel T11 tubes with $48 \mathrm{~mm}$ OD and $6 \mathrm{~mm}$ thickness for high pressure applications was carried out to study the micro structural changes occurring in thermo-mechanically affected zone (TMAZ). To qualify the process for the welding application where pressure could be 300bar.MIAB welds are studied with variations of arc current and arc rotation time. Experimental results reveal that TMAZ shows higher hardness than that in base metal and displays higher weld tensile strength and ductility due to bainitic transformation. The effect of arc current on the weld interface is also detailed and is found to be defect free at higher values of arc currents. The results 
of optical and SEM micrographs of TMAZ shows that base metal contains matrix of ferrite and pearlite, TMAZ1 along weld interface shows fine bainite with polygonal ferrite, Further the samples welded with higher arc rotation currents (290A) the microstructure shows defect free weld interface where as sample welded with lower arc rotation current the micro structure shows voids due to incomplete fusion. Thus the arc rotation time has a significant effect on microstructure.

This work (Biranchi Narayan Panda ,et al, 2016) presents a combined experimental and numerical study for investigating the arc speed of the T11 grade low alloy tubes in MIAB process. Various trials of experiments are conducted on the MIAB welding machine, and the arc speed is measured based on the four inputs (welding current, welding voltage, magnetic coil current, and voltage).,and a numerical approach of multi-gene genetic programming (MGGP) was used to formulate a functional relationship between arc speed and the four design variables. The statistical error metrics based on the square of correlation coefficient, relative error (\%), and root mean square were used to validate the model performance against the experimental data. The proposed model can be utilized to select the best combination of input variables to optimize the arc speed, which has a vital role in governing the weld quality. In addition, 2-D analysis conducted reveals that the welding current influence on the arc speed and followed by coil current and coil voltage. Author concludes that the predictions obtained from model are well in agreement with experimental data.

This study (S. Vignesh,et al, 2017) investigates the effect of MIAB welding parameters on T91 steel tubes and the experimental observations on the welded joints. The input parameters considered in the present work are welding current (900, 1000, 1100 A), tube thickness $(3.5,4.5,5.5 \mathrm{~mm})$ and weld time $(6,9,12 \mathrm{~s})$. The tensile strength and hardness measurements have been recorded and the cross sectional micro and macro images have been observed for the welded samples. Further, the welded specimens have undergone computed tomography and radiography tests. They concluded results as MIAB weld interface failures as a result of the presence of chromium enriched areas at the weld interface was identified and MIAB weld quality was analyzed with RT and CT images and it confirmed the crack formation in the weld region for the selected parameters, which in turn led to poor tensile strength.

This paper (R. Sivasankari, et al, 2017) aims at studying the formation of Light Band (LB) zone and its effect on the weld properties of MIAB welding of carbon steel tubes. A detailed micro structural analysis has been carried out to understand the micro structural transformations taking place in ThermoMechanically Affected Zone leading to formation of LB zone. Welded samples show better tensile properties with higher upset current as it eliminates LB zone formation at weld interface. Results reveals that welded tubes show a distinct white zone i.e. Light Band (LB) zone at the weld interface in the samples welded using lower upset current. This is due to the incomplete homogenization and incomplete expulsion of decarburized region at the weld interface.

\section{Conclusions}

1) Magnetic flux density in the gap between the pipes increases with increasing exciting current in the coil.

2) Arc rotation current playing a significant role in the formation of defect free weld at the interface. The lower arc rotation causes metallurgical defects.

3) The magnetic coil current and welding current are two major input parameters that govern the arc speed in MIAB welding process.

4) High electromagnetic force, greater the arc speed and better the weld quality.

5) It is important to maintain high current of $1100 \mathrm{~A}$ during last few milliseconds before forging to get a good weld quality.

6 ) The gap between tubes maintained at $2 \mathrm{~mm}$ and arcing current $220 \mathrm{~A}$ for obtaining good weldment.

7) The magnetic flux density required to accomplish slow rotation arc is 2.032 Tesla and $0.5 \mathrm{~A}$ exciting current in the magnetic coil system.

8) The advantages of MIAB welding are Short welding time, uniform heating, absence of pores and inclusions, high efficiency in mass production industries.

9) The component does not rotate during the process, no filler material is required, and no shielding gas is required.

10) Application in drive shafts, beam axle casings, petrol tank spouts, beam axles, propeller shafts and shock absorbers and piston rods.

11) Parameters such as gap size, exciting current in the coil and coil position from weld center, which influences the electromagnetic force generated in the welding process and weld quality.

12) Relatively small forgings forces compared to friction welding.

\section{References}

Taneko, A;Arakida, F;Takagi, K. (1987) Analysis of arc rotation velocity in magnetically impelled arc butt welding Welding International, 3:247-53.

Kuchuk and Yatsenko, (1988) Control of the Arc Moving in a Narrow Gap under the Effect of a Magnetic Field in PressWelding of Pipes. Welding International, 11, 965968.

Mori, S; Yasuda, K. (1989) Magnetically impelled arc butt welding of aluminum pipes. Welding International, 11 941-946

Sato,T.; Katayama, J.; Ioka, S; and Otani, M. (1991) An experimental study on rotational behavior of arc during magnetically impelled arc butt welding. Welding International, 5(1):5-10.

Kachinskiy, V.S.; Krivenko,V.G; Ignatenko, V.Yu. (2002) Magnetically impelled arc butt welding of hollow and solid parts. Doc. IIW-1564-02 Welding in the World, 46 (7-8), 49-56. 
Kim,J.W and Choi, D.H. (2003) A study on the numerical analysis of magnetic flux density by a solenoid for magnetically impelled arc butt welding. Proc. Institution of Mechanical Engineers Part B: Journal of Engineering Manufacture, 217, 1401-1407.

Fletcher, L.; Stecher, G.; Stubbs, C.; Norrish, J.; Cuiuri, D.; Moscrop, J. (2006) MIAB welding of oil and gas pipelines. In International Pipeline Conference; ASME: New York, 18.

Arungalai Vendan S, Manoharan S, Buvanashekaran G, Nagamani C (2008) Magnetic flux distribution modeling of magnetically impelled arc butt welding of steel tubes using finite element analysis. Inst Mech Eng, Part C: J Mech Eng Sci.

Arungalai Vendan, S., Manoharan, S., Buvanashekaran, G. and Nagamani, C., (2009) Development of a MIAB welding module and experimental analysis of rotational behavior of arc - Simulation of electromagnetic force distribution during MIAB welding of Steel pipes using Finite Element Analysis, International journal of Advanced Manufacturing Technology 43(13) , 1144-1156.

Kuchuk-Yatsenko, S.I., Kachinsky, V.S., and Ignatenko, V.Yu.,Goncharenko,E.I.;Koval,M.P. (2010) MagneticallyImpelled Arc Butt Welding of Pipes OF Steel X70, The Paton Welding Journal 7:29-31.

Iordachescu, D.; Iordachescu, M.; Georgescu, B.; Miranda, R.M.; Ruiz Hervias, J.; Oca na, J.L. (2010) Technological windows for MIAB welding of tubes featuring original longitudinal magnetization system with peripheral solenoids. Journal of Materials Processing Technology, 210, 951-960.

Kuchuk-Yatsenko, S.I., Kachinsky, V.S., and Ignatenko, V.Yu.,Goncharenko,E.I.;Koval,M.P. (2010)MagneticallyImpelled Arc Butt Welding of Parts of Automobile range of products, The Paton Welding Journal 6:28-31.

Arungalai Vendan S, Manoharan S, Buvanashekaran G, Nagamani C (2011)Magnetically impelled arc butt welding of alloy steel tubes in boilers establishment of parameter window. Mechatronics;21:30e7.
Iordachescu, D.; Iordachescu, M.; Lopez,R.; Miranda, R.M.; Garcia-Beltran,A. (2011) Characteristics of MIAB welding process and Joints Welding in the world. Vol. 55.

Arungalai Vendan, S;Manoharan, S; Buvanashekaran, G; Nagamani, C. (2011) MIAB welding of alloy steel tubes in pressure parts: metallurgical characterization and nondestructive testing. J Manuf Process, 14:82e8.

Arungalai Vendan, S; Manoharan, S; Buvanashekaran, G; Nagamani, C. (2012) Strength assessment using destructive testing on MIAB welded alloy steel tube and subsequent techno-economical evaluation. J Manuf. Process; 14:328e35.

Berna Balta and Kocaeli. (2014) Magnetic impelled arc butt welding implementation on truck chassis components.International Manufacturing science and Engineering Conference; ASME: Michigan, USA.

Sivasankari R, Balusamy V, Buvanashekaran G. (2014) Effect of upset current in magnetically impelled arc butt (MIAB) welding of carbon steel tubes.Appl Mech Mater :592e4. $240 \mathrm{e} 244$

Sivasankari R, Balusamy V,Venkateswaran P.R, Buvanashekaran G,Ganesh kumar K. (2015) Characterization of magnetically impelled arc butt welded T11 tubes for high pressure applications. Def Tech 11(3):244-54

Biranchi Narayana p,Arungalai Vendan, Akhil G. (2016) Experimental - and numerical - based studies for magnetically impelled arc butt welding of T11 chromium alloy tubes.Int.J.Adv.Manuf.Tech.

Vignesh S, Dinesh Babu P, Prasanna Venkatesh V, Martin Vinoth S, and Marimuthu P. (2017) Experimental Investigations on Magnetically impelled arc butt welded T91 steel tubes, Trans. Indian Inst. Met.

Sivasankari R, Balusamy V,Venkateswaran P.R, Buvanashekaran G,Ganesh kumar K. (2017) Light Band zone formation and its influence on properties of Magnetically Impelled arc Butt Welded (MIAB) welded carbon steel tubes, Trans. Indian Inst. Met. 